\title{
ANASSESSMENT OF THE SOIL-CONDITIONING CAPACITY OF GUMS EXUDED BY SOME TREES IN SIERRA LEONE II: RAINDROP EXPERIMENTS
}

\author{
Yormah, T.B.R. and Egbenda, P.O. \\ Department of Chemistry, Fourah Bay College, University of Sierra Leone, Freetown
}

\begin{abstract}
This study assesses the soil conditioning capacity of tree gums based on the level of resistance to crumble posed by moulds of treated soils to the impacts of artificial raindrops. Gums exuded by trees viz., Acacia occidental and Parkia bicolor as well as a sample of poly(vinyl) alcohol (PVA) were used as soil conditioners. The soil samples were a loam, laterite and a leached sandy soil, labeled $A, B$ and $C$, respectively. The study shows that compared to PVA (an established synthetic soil conditioner), treatments by the tree gums conferred greater conditioning capacity to the soil samples; the conditioning effectiveness of the tree gums was in the order P. bicolor >A. occidentale $>P V A$. The effectiveness of the all the conditioners increased with concentration with a somewhat leveling effect at high concentrations. An appreciable degree of stability to the raindrops (96.6, 111 and $114 \%$ for samples $B, A$ and $C$, respectively) was imparted to the soil samples when they were treated with $1 \%(w / v) \mathrm{CaCl}_{2}$ solution on its own; prior treatment of the soil samples with the $\mathrm{CaCl}_{2}$ solution enhanced the soil conditioning properties of the tree gums as well as the PVA. The soil conditioning effect was most pronounced in the case of sample B (the lateritic soil) and least pronounced in the case of sample $C$ (the leached sandy soil). These results are interpreted in terms of the physico-chemical properties of the conditioners and of the soil samples.
\end{abstract}

\section{INTRODUCTION}

Soil fertility is a general term that refers to the various factors that promote and support plant growth. The factors that impact plant growth can be classified into two broad categories: (i) the nutrient factors and (ii) the soil factors. The nutrient factor refers to the presence and intensity of the various nutrients that are necessary for plant growth and is formally referred to as chemical fertility. The soil factor refers to the condition/state of the soil that enables plants to take fuller advantage of the presence of soil nutrients resulting to optimal growth. This category/class of soil fertility is formally referred to as physical fertility. Physical fertility also embodies the capacity of the soil to (1) control/limit land based environmental pollution by immobilising pollutants to enable their destruction by microorganism and (2) minimize soil loss through erosion by preventing/minimizing the disintegration of soil structure.
The foundation/basis of soil physical fertility is soil structure. Soil structure refers to the size, shape and arrangement of the aggregates formed when primary particles are clustered together into larger separable units, called 'peds'. The genesis of soil aggregate formation is the association of clay particles into quasi-crystals and/ or domains and/or tactoids. The term 'quasi-crystal' refers to the rather compact stacking of montmorillonite clay particles; the stacking in the (001) direction being crystallike. The term 'domain' refers to the relatively looser parallel arrangement of platelets of illite-type clay minerals in such a way as to allow the full penetration of $\mathrm{N}_{2}$ molecules into the interlayer spaces. 'Tactoids', on the other hand, are formed when clay particles associate randomly instead of as packets of perfectly orientated platelets.

Soil clay platelets within quasi-crystals, domains, and tactoids are usually held and kept together, largely by weak van der Waals forces, which are easily disrupted by hydration/solvation forces. Domains and/or quasi-crystals 
and/or tactoids are also attached to one another and to larger sand and silt particles by relatively weak bonds as proposed by Emerson (1959). This therefore gives rise to the need for additional bonding/cementing agents in order to produce larger aggregates and to stabilize the resulting soil structure against disruptive forces (water, wind, mechanical, etc.). Natural as well as synthetic polymeric substances are known to fulfill this role.

The process of artificially ameliorating and/or stabilizing soil structure is known as soil conditioning.

Polysaccharides are among the more important natural soilconditioning agents. These polymers are believed (Burchill, et al., 1981; Cheshire and Hayes, 1990) to bring about inter-particle bonding by means of (electrostatic) interactions between charged entities (including chargeneutralising cations) on the surface of the soil colloids and functional groups on the polymer strands.

An important consequence of the model of soil aggregate formation described above is that when domains, tactoids, sand, and silt particles, etc. associate to form macroaggregates, and eventually soil crumbs, peds, etc., numerous pore channels ramify the resulting structure leading to the formation of a spatial network of soil particles commonly referred to as 'soil fabric'. The term soil fabric is sometimes also referred to as soil structure.

It is the state/characteristics of the soil fabric that reflects the physical fertility of a soil. The size and shape of the soil aggregates determines the size of the soil pores. For particles of similar shape, the larger the soil aggregates the larger the soil pores and the lower the bulk density of the soil. Also, the larger the soil aggregates the higher the level of aeration, the higher the ease of root penetration and shoot emergence, and the higher the drainage. Naturally, the higher the drainage of a soil the lower will be its water holding/retention capacity. At the other extreme, soils consisting of very small aggregates (e.g. clayey soils) have low aeration, high bulk density, low ease of root penetration and shoot emergence, very poor/low drainage and are therefore easily waterlogged. The conclusion to be drawn from the foregoing is that a physically fertile soil should neither be exclusively composed of very large nor of very small aggregates. Soils with optimal physical fertility must therefore be composed of aggregates of optimal sizes as exemplified by those that constitute a loamy soil. A typical loamy soil is one that is composed of 35-50 $\%$ sand, 35-45 \% silt and 15-25\% clay (see Russell E. W. 1973). About $50 \%$ of the volume of such a soil consists of pore space. Under optimal plant growing conditions one half of this pore space is filled with water/moisture and the other half with air.

What is perhaps more important to physical fertility is the stability and maintenance of this desirable/loam structure in the face of adverse/disruptive forces in the environment. The forces that disrupt soil aggregates include rainfall, wind, the trampling effect of grazing animals, etc.

As has been mentioned above natural and synthetic polymeric substances are used to modify the sizes of soil aggregates to attain a structure akin to that of a loam and to stabilize the resulting structure. The indices of soil physical fertility therefore include measurement of:

$>$ Particle size distribution via dry and wet sieving.

$>$ Resistance to the disruptive forces of rainfall.

$>$ Resistance to crusting through compaction tests.

$>$ Saturated hydraulic conductivity based on Darcy's law.

$>$ Bulk density.

> Water holding/retention capacity based on moisture content.

This work is based on the measurement of resistance of the soil aggregates to the disruptive forces of raindrops.

\section{EXPERIMENTAL}

\section{Description of soil samples}

The samples were carefully selected in order to reflect differences in structural characteristics; the samples were all collected from the top $15 \mathrm{~cm}$ of the respective profiles.

Sample A: This meticulously selected loamy soil (with good crumb structure - the type that is easily recognized as a good agricultural soil) was collected from a piece of land belonging to Province J of the Soil Map Sierra Leone (Odell, 1974); this piece of land had not been cultivated for at least 10 years. This sample was mechanically analysed by the wet-sieving and pipette methods (BSI $377 / 1975$ ) and found to be composed of $30 \%$ sand, $28 \%$ clay and $42 \%$ silt.

Sample B: This rather 'structureless', reddish-brown lateritic soil was collected from an eroded excavated wasteland belonging to Province A of the Soil Map of Sierra Leone. 

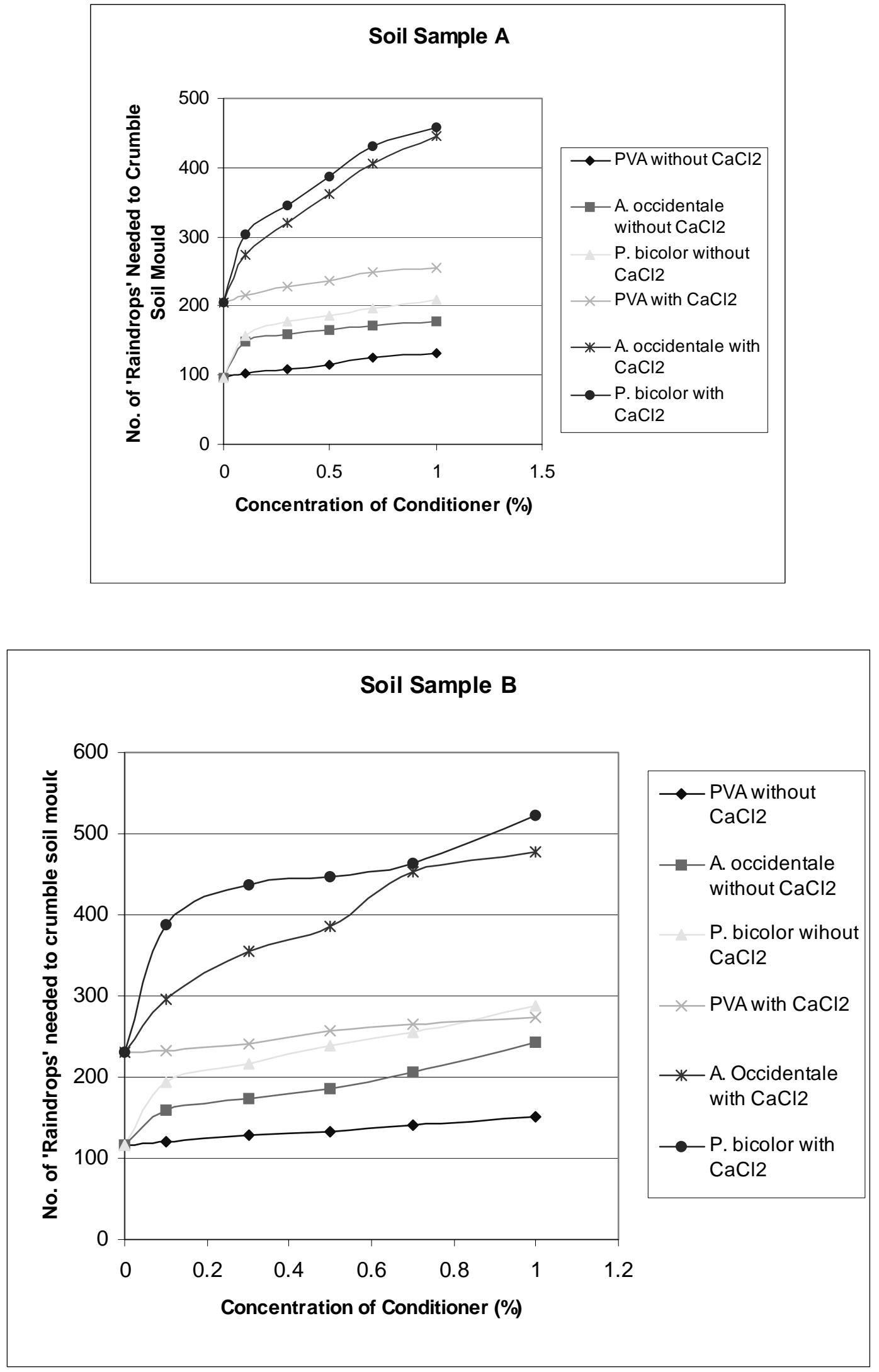


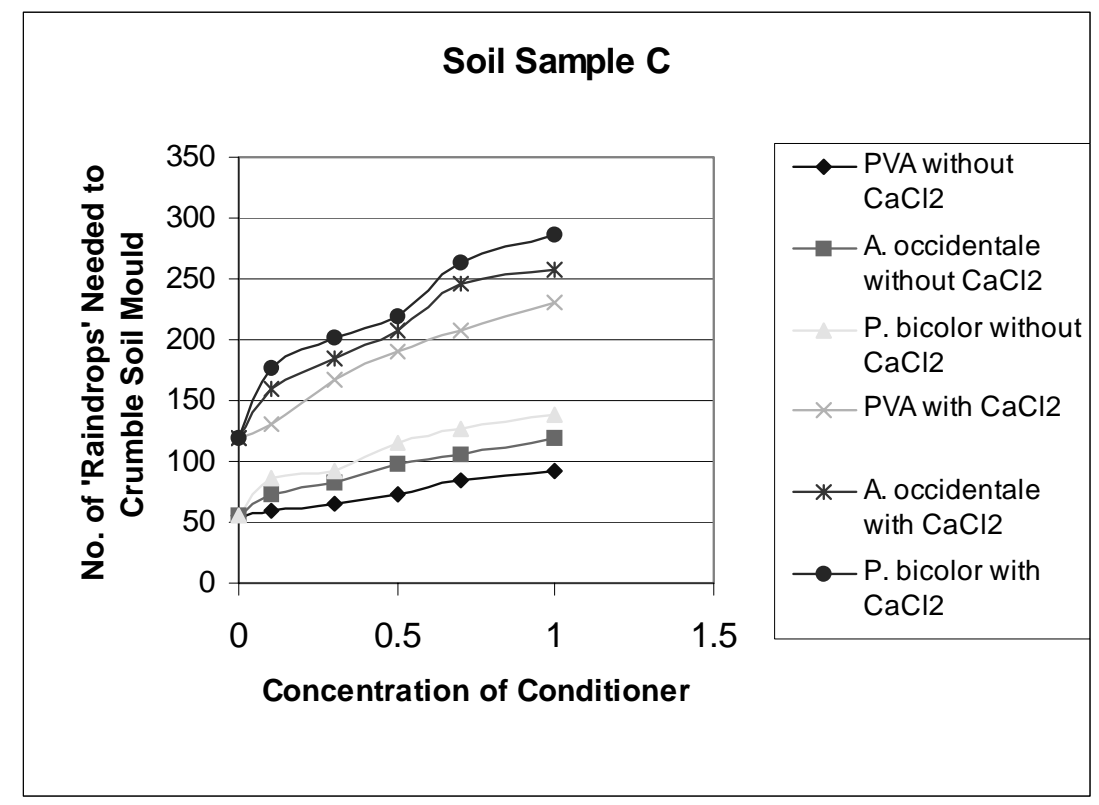

Sample C: This light, highly leached sandy soil was collected from a deposited run-off originating from a slashand-burn wasteland belonging to Province J.

\section{Chracterisation of Soil and Gum Samples}

The soil samples were further characterized in terms of their $\mathrm{pH}$, Cation Exchange Capacity (CEC), and organic mater (OM) and free iron oxide contents. The CEC was determined by the ${ }^{22} \mathrm{Na}$ isotope dilution technique in a Britton-Robinson buffer solution at $\mathrm{pH} 6.4$; the OM content was determined by the Walkley-Black (see Allison, 1965); the free iron oxide content was determined by the sodium-dithionite method (Olson, 1965); the $\mathrm{pH}$ was determined in $1 \mathrm{M} \mathrm{KC1}$ using a 1:2.5 ratio of soil:liquid. A summary of the results is given in Table 1.

Table 1. Relevant physio-chemical properties of the soil samples

\begin{tabular}{|l|l|l|l|l|}
\hline Sample & $\begin{array}{l}\text { PH } \\
(\mathbf{1 M ~ K C 1 )})\end{array}$ & $\begin{array}{l}\text { CEC } \\
(\mathbf{C m o l} / \mathbf{K g})\end{array}$ & $\begin{array}{l}\text { OM } \\
\text { content }(\boldsymbol{\%})\end{array}$ & $\begin{array}{l}\text { Iron Oxide } \\
\text { content }(\%)\end{array}$ \\
\hline A & 4.4 & 16.5 & 5.1 & 9.4 \\
\hline B & 5.6 & 3.1 & 2.8 & 2.0 \\
\hline C & 7.6 & 2.7 & 0.8 & 0.3 \\
\hline
\end{tabular}

Samples of the plants gums were collected from $A$. occidentale and P. bicolor. These gums were purified by separately dissolving about $50 \mathrm{~g}$ of each sample in 200 $\mathrm{cm}^{3}$ of distilled water. The solutions were then filtered and just enough ethanol (95\%) to effect precipitation was gradually added to the filtrate. The yield in the case of $A$. occidentale was $68 \%$ and that in the case of $P$. bicolor was $38 \%$. The ash content and the relative viscosity (in distilled water) had previously been determined (Table 2). The molecular weight of the PVA sample was given as $1.4 \times 10^{4}$.

Table 2: Some properties of the conditioners

\begin{tabular}{|l|c|c|}
\hline Sample & Ash content (\%) & Relative viscosity \\
\hline A. occidentale & 0.54 & 1.1 \\
\hline P.bicolor & 0.93 & 19.8 \\
\hline PVA & 0.05 & 0.7 \\
\hline
\end{tabular}

\section{Application of conditioners to soil samples}

Each soil sample was treated with various concentrations viz., 0 (i.e., distilled water), 0.1, 0.3, 0.5, 0.7 and $1.0 \%$ (w/v) of the conditioners in distilled water using a device constructed locally. The d" $2 \mathrm{~mm}$ fraction of each soil sample was first carefully and uniformly packed in a 
cylindrical glass column, having a diameter of $3.2 \mathrm{~cm}$ and a total length of $19.5 \mathrm{~cm}$; a screen support (to hold the soil column in place and to prevent the soil particles from falling through) had been fitted at one end which was then drawn into a funnel-shape and became the bottom end. This end was connected to a glass reservoir containing the solution of the conditioner (or $\mathrm{CaCl}_{2}$ solution or distilled water) by means of flexible PVC tubing. The height of the reservoir was then adjusted in order to get its liquid content to flow upwards into the soil sample via the perforated screen-support base of the glass column. The flow of the liquid was carefully (mechanically) controlled in order to just saturate the soil sample to 'field capacity' and to achieve a reproducible and slow rate of wetting. The samples were each kept saturated in this manner for 6 hours, after which the solution of the conditioner (or distilled water) was allowed to drain out of the soil. The soil samples were then air-dried in situ (i.e., undisturbed and while still in the glass column) for 4 days. Another treatment involved saturating the soil samples (as described above) with $1 \% \mathrm{CaCl}_{2}$ solution and then followed by another bout of saturation with a particular concentration of the conditioner solution.

\section{Raindrop Experiment}

About $20 \mathrm{~g}$ of the conditioner-treated soil was pressed and moulded into a cylindrical core using a small plastic mould $(3.4 \mathrm{~cm}$ in diameter and $1.8 \mathrm{~cm}$ in height). The uniformly-produced soil moulds which served as giant aggregates, were left to dry for five days after which they were subjected to the impacts of artificial raindrops, falling from a distance of $30 \mathrm{~cm}$, using the apparatus described by McCalla (1944). This apparatus consisted of a $250 \mathrm{ml}$ separating funnel (BS 2021) fitted at the top with a Tshape still head (quick-fit) that allows water to flow in and out. Thus there was a constant head of water above the falling 'rain drops'. Drops of similar size ( $5 \mathrm{~mm}$ diameter) were regulated to fall at a rate of 100 drops per minute for every determination (see also Bruce-Okine and Lal, 1975).

The stability of the soil cylinders were evaluated by determining the number of drops of 'rain' that were required to completely disintegrate/crumble a soil aggregate represented by a moulded soil core.

The results used to produce Figs. and are averages of three nearly consistent results.

\section{RESULTS OFRAINDROPEXPERIMENT}

Results of these experiments show that samples treated with water alone were less resistant to the impact of the 'rain drops' than those treated with the conditioners; soil aggregate stability increased as the concentration of the conditioners increased, with a somewhat leveling effect at high conditioner concentration. This effect was more pronounced in the case of sample B (the lateritic soil) than for the other samples. Since these soils, like most tropical soils, consist mainly of kaolinite clay minerals and soil oxides as the mineral components they probably interacted with the polymeric strands of the polysaccharides plant gums and of the PVA via the 'loopsand-tails' mechanism proposed by Kavanagh et al. (1978).

The application of calcium on its own imparted an appreciable degree of stability to the soils $(96.6,111$, and $114 \%$ for samples $\mathrm{B}, \mathrm{A}$, and $\mathrm{C}$, respectively). The application of the plant gums together with calcium ions was also seen to enhance the innate soil conditioning capacity of the plant gums and the PVA. Similar results were obtained when the saturated hydraulic conductivity of the soils and changes in particle-size distribution (using wet and dry sieving) were used as the indices of the soil conditioning capacity of the conditioners (see Yormah and Egbenda, 1995; Egbenda and Yormah, 1995). These results emphasize the role of the resident cations in the binding of the polymers to the soil colloids. Under this condition the weaker $\mathrm{H}$-bonding via which some polymeric conditioner molecules are attached to the soil particles (in the absence of the $\mathrm{Ca}^{2+}$ ) would be replaced by the relatively stronger bonds involving cation-bridging (Yormah and Egbenda, 1995). Mortensen (1962) has also suggested that the polyvalent resident cations, by their ability to suppress/reduce the thickness of the double layer around the soil colloids, will allow the conditioner molecules to approach the surface much closer. This greater proximity, he argues, increases the chances for soil-surface/ conditioner interactions.

The trend in effectiveness of the conditioners was in the order $P$. bicolor $>$ A. Occidentale $>$ PVA. (It was not possible to mould samples treated with $A$. communis into a rigid core, it invariably collapsed when touched by the fingers. The same samples were made into perfect moulds after treatment with just distilled water.) This result can be rationalised by considering the relative molecular masses of the soil conditioners. Although actual molecular masses of the tree gums could not be determined, an indication of the relative molar masses can be obtained from values of the relative viscosities reported in Table 2: there is an obvious direct relationship between viscosity and molecular mass. Thus the molecular masses of the conditioners would be expected to be in the order $P$. bicolor $>$ A. occidentale $>$ PVA. The fact that the molecular mass of the PVA sample was given as $1.4 \times 10^{4}$ and the 
molecular mass of a gum exuded by P. bicolor growing in Nigeria has been reported as $3.0 \times 10^{6}$ (see Anderson, et al. 1985) gives some credence to this deduction. The results therefore show that $P$. bicolor with the highest molecular mass and therefore with the longest polymer strands has the highest capacity to aggregate and stabilize soil particles. PVA with the lowest viscosity and therefore lowest molecular mass has the least soil-conditioning capacity. Williams et al. (1966) and Carr and Greenland (see Burchill et al. 1981) who had obtained similar results have argued that although polymer penetration into the soil pores is greatest for the lowest molecular mass material, the lesser amounts of the highest molecular mass material that is sorbed confers the greatest aggregate stability.

Of the 3 distilled water-treated soil samples, the loamy soil (sample A) showed the greatest resistance to the 'raindrops'. It is noted that sample A also contains the highest organic matter content. Previous work by other researchers has established that soil organic matter enables soils to withstand stresses caused by rapid wetting and by the impact of raindrops (Gabriels and Michiels, 1991).

\section{REFERENCES}

Anderson, D. M. W. and De Pinto, G. L.(1985). Studies of uronic acid materials. 71. Gum polysaccharides from three Parkia species. Phytochemistry, 24, 77-79.

Allison, L. E.: Organic carbon. In Methods of Soil Analysis. (C. A. Black, Ed). Agron. Series 9 Am Soc Agron., Madison, Wisconsin, 1367-1378.

Bruce-Okine, E. and Lal, R.(1975) Erodibility as determined by raindrop technique. Soil Sci., 119, 149-157.

BSI 1377/1975 (1975). BRITISH STANDARDS INSTITUTION, (BSI1377). BSI London

Burchill, S., Hayes, M. H. B. and Greenland, D. J.(1981). Adsorption of organic molecules. In The Chemistry of Soil Processes (D. J. Greenland and M. H. B. Hayes Eds.) J. Wiley Chicester, 221-400.

Chesire, M. V. and Hayes, M. H. B. (1990). Composition, origins, structures, and reactivities of soil polysaccharides. In Soil Colloids and their Associations in Aggregates. (M. F. De Boodt, M. H. B. Hayes, and A. Herbillon. Eds.) Plenum Press, New York, 517-556.

Emerson, W. W., The Structure of soil crumbs. J. Soil Sci. 10, 235-244, 1959.

De Boodt M.F.: Application of polymeric substances as physical soil conditioners. In: Soil Colloids and Their Associations in Aggregates. (M.F. De Boodt, M.H.B. Hayes and A. Herbillon, Eds.). Plenum Press, New York, 517-556, 1990
Egbenda, P.O. and Yormah, T. B. R.: A comparative study of the effectiveness of polysaccharide gums and a synthetic polymer in the formation of water-stable aggregates in selected tropical soils. J. Pure \& Appl. Sci. (USL), 4:18-25, 1995.

Emerson, W. W., Forster R. C. and Oades, J. M.: Organomineral complexes in relation to soil aggregation and structure. In: Interactions of Soil Minerals with Natural Organics and Microbes. (P.M. Haung and M. Schinitzer, Eds.). Special Publication No. 17, Soil Sci. Soc. Am., Inc., Madison, Wisconsin, 1986.

Gabriels, D. and Michiels, P. Soil organic matter and water erosion processes. In Advances in Soil Organic Matter Research: The Impact on Agriculture and the Environment. (W. S. Wilson, Ed.). Royal Society of Chemistry, 1991.

Greenland D.J., Linstrum G.R. and Quirk J.P.: Role of polysaccharides in stabilisation of natural soil aggregates, Nature (London), 191, 1283-1284.1961.

Haworth, W. N., Pinard F. W. and Stacey, M.: Function of bacterial polysaccharides in soil. Nature (London), 158, 836-837, 1946.

Kavanagh B.W., Posner A.M. and Quirk, J.P. The adsorption of poly(vinyl alcohol) on gibbsite and goethite. J. Soil Sci. 27,467-477.1976.

Kawanagh B.V., Posner A.M. and Quirk, J.P.: Adsorption of PVA on soil colloids. In: Modification of Soil Structure (Eds W. W. Emerson, R.D. Bond and A. R. Dexter), J. Wiley, Chicester, 1978.

McCalla, M. T.: Water-drop method of determining stability of soil structure. Soil Sci. 58, 117-21, 1944.

Marshall, T. J. and Holmes, J. W.: Soil Physics. Cambridge, pp 188, 1979

Martin J.P.: Micro-organisms and soil aggregation: II. Influence of bacterial polysaccharides on soil structure. Soil Sci., 61, 157-166,1946.

Mortensen J. L.: Adsorption of hydrolysed poly(acrylonitrile) on Kaolinite. Clays Clay Minerals 9, 530-545, 1962.

Murray R.S. and Quirk J.P.: Interparticle forces in relation to the stability of soil aggregate. In: Soil (Colloids and Their Association in Aggregates; Eds. M. F. De Boodt, M.H.B. Hayes and A. Herbillon). Plenum Press, New York, 439-461, 1990.

Odell R.T., Dijkerman J.C., van Vuure W., Melsted S.W., Beavers A.H. and Sutton P.M.: Characteristics, classification and adaptation of soils in selected areas in Sierra Leone, West Africa. A Report of Cooperative Research - Agronomy Dept., Njala Univ. College, Univ. of Sierra Leone, Bull. 4 and Univ. of Illinois, Bull., 748, 1974. 
Olson, R. V.: Iron. In Methods of Soil Analysis. (C. A. Black, Ed.) Agron. Series 9 Am Soc, Agron., Madison, 963-975, 1965.

Richardson, S. J.: Effect of artificial weathering on the soil structural stability of a dispersed silt clay. J. Soil Sci. 27, 287-94, 1976.

Russell, E. W.: Soil conditions and plant growth, $10^{\text {th }}$ edn. Longmans, London, 1973

Schamp N., Huylebroeck J. and Sadones, M.: Adhesion and adsorption phenomena in soil conditioning. In: Soil Conditioners (B.A. Stewart, Ed.), Soil Sci. Soc. Am., Spec. Publ. No 7. Soil Sci. Soc. Am., Inc., Madison, 13-24, 1975.

Schamp N., Goor G., Sadones M., Bernaert E. and Callebaut, F.: Optimisation of polymer emulsions as soil conditioners. In: Modification of Soil Structure (Eds W.W. Emerson, R.D. Bond and A. R. Dexter), J. Wiley, Chicester, 151-155, 1978.
Sutton P. M., Whiteside E. P. and Odell R .T.: Some Sierra Leone soils: 1 . Physical and chemical properties, 2. Mineralogy, micromophology and classification. Soil Sci. 148, 29-38 and 102-113, (respectively), 1989.

Theng B. K. G.: Formation and Properties of Clay-Polymer Complexes. Elsevier, Amsterdam, 1979.

Williams B. G., Greenland D. J. and Quirk J.P.: The adsorption of poly (vinyl alcohol) by natural soil aggregates. Aust. J. Soil Res., 4, 131-143, 1966.

Yormah, T. B. R. and Egbenda, P. O.: An assessment of the soil-conditioning capacity of gums exuded by some trees in Sierra Leone: I. Hydraulic conductivity measurements. Int. Agrophysics, 9:55-65. 